\section{Libya and human values}

\section{Death sentences issued by a Libyan court highlight more than one type of injustice.}

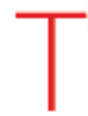

he huge international outcry that followed last month's unjust decision by a Libyan judge to sentence six health professionals to death is hardly surprising. The charge that they deliberately infected more than 400 children with HIV in 1998 was baseless. The authorities ignored a body of evidence demonstrating that the cause of the outbreak was the use of contaminated medical material in the hospital in Benghazi, and that many of the children were infectedlong before the medics even began working at the hospital (see page 7).

Libya has responded vigorously to the international community's reassertion that it should ensure a fair and impartial trial, and for scientific evidence to be taken in account. Its foreign ministry has denounced Western political interference as creating a dangerous precedent in which Libyans are considered "sub-human" and treated differently from Bulgarians. It added that the political stance expressed by the Bulgarian government, European Union countries and others shows "a clear bias to certain values that are likely to trigger wars, conflicts and cause enmity between religions and civilizations".

It would be too simplistic to dismiss this entirely as anti-Western rhetoric. There is understandable resentment in many parts of the world that powerful nations are selective and inconsistent in their application of human rights. But the attention attracted by the Libyan scandal has been largely fuelled by the social conscience of what can in such instances be justifiably called the international scientific community - a force that is largely apolitical. It has a long track record in defending individuals on trial in human-rights cases, and has helped Arab and other scientists who have suffered travel restrictions to the United States (see Nature 443, 605-606; 2006). It has also been relatively even-handed in its struggle to champion science as a rational means of establishing truth, and has consistently attacked the abuse of science for political ends wherever this occurs.

The case of the health professionals is an eminently scientific one, and the protests of the global scientific community are a defence not of Western values, but of universal and fundamental values, induding the basic right to a fair and impartial trial, and to be allowed to present all the evidence. These are values to which Libya itself subscribes, having signed many international human-rights treaties.

But the Libyan case also involves other values. The first is the humanitarian value of alleviating the tragedy of the infected children. An international fund has been set up to help treat the children in European hospitals, and to strengthen Libya's expertise in dealing with HIV. The international community should continue to strengthen these efforts as part of its solidarity with both the Libyan people and the affected families.

The unfortunate politicization of this case has also diverted attention from another value: the right to safe health care. The transmission of HIV in medical settings in many countries
"The protests of the scientific community are a defence of universal values, including the basic right to a fair and impartial trial." is a large but often 'invisible' problem that is only heard about when it reaches the scale of the Benghazi outbreak, or one in Kazakhstan last summer in which almost 100 children were infected with HIV. There is no internationally recognized set of precautions to make procedures safer, and many nations lack adequate medical supplies and must risk re-using them.

The scientific community, faced with the injustice of the Libyan trial, has acted resolutely. But it must do more to press home the less immediately compelling but equally tragic battlegrounds that the Libyan case highlights in the fight against HIV.

\section{Enter Nature Photonics}

O ver the past 50 years, the field of photonics - the scientific study and application of light - has blossomed to become one of the most important enabling technologies of our time. The development of devices such as the laser, the light-emitting diode, the low-loss optical fibre and the $\mathrm{CCD}$ (charge-coupled device) detector have transformed the world around us, improving performance in applications such as data communication, materials processing, imaging, biomedicine, lighting and home entertainment.

Fundamental research in photonics is compelling in its own right and promises further transformational technologies. For example, the creation of artificial materials with a negative refractive index is not only cutting-edge multidisciplinary research but holds out the prospect of increasingly high resolution in the detection of, and processing by, light. Engineering materials that trap photons in 'photonic crystals' will, it is hoped, lead to new types of optical memory, and the development of silicon-based all-optical circuits is expected to transform the fields of communications and computation.
Given the excitement and importance of photonics, there is plenty of scope for a journal that captures outstanding research as well as the technologies and their impacts, including commercial developments, and that caters for anyone seriously interested in photonic science and engineering. Accordingly, this month sees the launch of Nature Photonics (see www.nature.com/nphoton), whose first issue contains articles spanning the above topics and more.

Nature itself will continue to publish high-impact papers in photonics - the launches of research journals including Nature Physics, Nature Materials and Nature Nanotechnology have never diluted Nature's role in their respective disciplines, but have provided new outlets for top-quality research and discussion.

In publishing terms, Nature Photonics is distinctive among the Nature group of journals in being the first to have its editorial headquarters in our offices in Tokyo (supported by associate editors in London and San Francisco). This development will further strengthen editorial links with the research community in Asia Pacific, which is particularly strong in photonics. However, like all Nature journals, Nature Photonics is truly international and will publish research from around the globe without geographical preference. 